\title{
УСКОЛЬЗАЮЩАЯ «ЭТНИЧНОСТЬ»
}

\section{Рецензия на книгу «Социальные факторы межэтнической напряженности в России»}

\section{ЕЛЕНА ФИЛИППОВА}

\begin{abstract}
В русле сформировавшейся в отечественной школе этносочиологии традиции рассматривать сочииальные взаимодействия, противоречия и конфликты сквозь призму «межэтнических отнотений» центральным понятием рецензируемого труда является «межэтническая напряженность». Насколько оправданна такая универсализация «этничности» в качестве объяснительного механизма общественных процессов, что она объясняет и что не может объяснить? К чему приводит абсолютизация этничности как свойства, «имманентно присущего» каждому индивиду и предопределяющего его принадлежность к группе? Эти и другие вопросы обсуждаются в рецензии.
\end{abstract}

Ключевые слова: этничность, межэтническая напряженность, этноцентризм, группоцентризм, государствоцентризм.

Монография коллектива российских социологов «Социальные факторы межэтнической напряженности в России» ${ }^{1}$, посвященная фантомному явлению «межэтнических отношений», наводит на множество размышлений, прежде всего по поводу утвердившейся в наших гуманитарных науках концептуальной рамки, которую можно назвать «этнической призмой», или «этническими очками». Критическим моментом в развитии общественных наук в СССР, приведшим к такому положению, следует, очевидно, считать рождение в середине 1970-х годов на стыке этнографии и социологии новой смежной дисциплины этносоциологии. До этого момента советская этнография мало интересовалась современностью и не пыталась применять количественные методы, а деформированная и оторванная от общемирового развития советская социология, как это не покажется странным сегодняшнему читателю, практически не обращала внимания на «этнический» фактор.

Во второй половине 1970-х - 1980-х годах сформировалась устойчивая практика «массовых этносоциологических опросов», сопровождавшаяся усилиями этнографов по поиску признаков, индикаторов, компонентов «этничности», претендующих на объективность и поддающихся количественной оценке. Учитывая глубоко субъективную, изменчивую и трудноуловимую природу этничности, задача эта в принципе невыполнима. Тем не менее разрабатывались громоздкие многостраничные анкеты, одни и те же вопросы кочевали из исследования в исследование. В наши дни социологи во всем мире, и в России в том числе, уделяют все больше внимания качественным (этнографическим) методам, прежде всего углубленному интервью. Однако традиция «массовых опросов» сохраняется.

ЕлЕНА ИвАНОВНА ФИлиППовА (elena_filippova89@yahoo.fr), ИНСТиТут ЭТНОЛогии и АНТРОПолоГии РАН, Россия.

РЕЦЕНЗИЯ ПОСТУПИЛА В РЕДАКЦИЮ В МАРТЕ 2019 Г.

\footnotetext{
${ }^{1}$ При цитировании или отсылке к данной книге будет даваться только номер страницы.
} 
В значительной мере ее поддерживает доверие к цифрам, характерное для существенной части чиновников и управленцев, формирующих социальный заказ на такие исследования, а также журналистов, охотно тиражирующих их результаты. Сами ученые тоже уверены, что создают «эффективные инструменты диагностики межэтнических отношений, позволяющие отслеживать возможные факторы напряженности и формировать основы успешной политики, предупреждения межэтнических конфликтов в российском обществе» [9-10]. Проблема в том, что массовые опросы не только (и даже не столько) фиксируют социальные процессы, которые у нас в стране принято называть «межэтническими отношениями», не только отражают общественные представления на этот счет, но и формируют их.

Рецензируемый труд интересен тем, что его авторы предлагают встроить «этничность» в более широкий концептуальный контекст, рассматривая «межэтническую напряженность как состояние, имеющее в основании совокупность причин социального, экономического и политического характера» [6]. В соответствии с таким пониманием предмета исследовательский коллектив отдельно рассматривает «социокультурные» и «социально-экономические» факторы (подчеркнем, именно в такой последовательности), лежащие в основе изучаемого феномена. Книгу открывает историографический раздел, содержащий обзор западных социальных теорий, по-разному оперирующих понятием этничности: в контексте ли отношений большинства/меньшинства и социального неравенства или в контексте зарождения национализма; с позиций социального конструктивизма или с позиций примордиализма и культурной составляющей. Отдельно обсуждается соотношение теорий этничности и классовой теории. Возвращение марксизма на подобающее ему место в кругу социологических концепций после десятилетий некритичного цитирования в советские годы и поспешного забвения в постсоветские можно только приветствовать, тем более что все это время мировая социология активно работала с этим наследием, развивая одни его положения и полемизируя с другими.

Совершенно справедливы утверждения авторов рецензируемой монографии о том, что «этнические теории, заменившие собой деление на расы, вобрали в себя прежнюю логику господства и подчинения» [16], что источником «межэтнической напряженности и межэтнических противоречий» является деление населения на доминирующее большинство и меньшинства [17], а также что любые идеологии, включая национализм и ксенофобию, «подпитываются политиями, входящими в политический класс» [24]. Справедливо и объяснение механизма возникновения этничности в либеральных демократических обществах [43], рассуждая о котором, авторы рассматривают этнические группы как одну из разновидностей социальных групп, как символический, социальный и политический ресурс, способный увеличить личный социальный капитал. Можно согласиться и с опасением, что «явление прекаризации... способно стать ... серьезным стимулом этнической мобилизации» [47], основанным на признании того факта, что «не сама по себе этноконтактная ситуация, а усиливающаяся конкуренция за ресурсы вызывает к жизни ... аверсивные установки» [49]. Наконец, авторы абсолютно правы в том, что «огромная, если не решающая роль в воспроизводстве межэтнической напряженности принадлежит государству и другим властным институтам» [7]. 
Однако нельзя не отметить, что наличие такого объекта, как «межэтнические отношения» (способного принимать форму «межэтнической напряженности» или «межэтнического конфликта») постулируется в книге как бы по умолчанию, а это означает признание безусловного существования субъектов таких отношений - «этносов» или «этнических групп». Вопреки призыву изучать межэтническую напряженность «в русле методологического индивидуализма» [55], господство этнической парадигмы в системе представлений авторов прослеживается уже в заглавии первого раздела, где присутствует словосочетание «межэтнические исследования» (что это такое, трудно понять). Данное выражение можно было бы счесть языковой небрежностью, но она неслучайна. Так, из текста следует, что «этнические проблемы» существовали, видимо, от сотворения мира, поскольку даже в сословно-кастовом обществе наличествовали якобы группы, выделявшиеся по этническому принципу (в действительности все наоборот: многие из считающихся сегодня «этническими» категории возникли в результате этнизации социально-профессиональных, родовых или кастовых сообществ. Это не только хрестоматийные, но экзотические для российского читателя хуту и тутси, но и более близкие нам башкиры или тептяри - примеров можно привести множество). Со средневековья существовали, по мысли авторов, «этнические проблемы», которые лишь «обострились» с наступлением Нового времени (правильнее было бы сказать, что увязывание культуры с «происхождением» и превращение еe в основной разграничительный маркер стало реакцией на разрушение сословных перегородок). Утверждая, что «этнические или расовые конфликты случаются чаще и протекают острее, чем конфликты, обусловленные разными социальными позициями вовлеченных в них акторов» [7], было бы нелишним вспомнить о накале ожесточенности и масштабе потерь в ходе гражданской войны и большого террора как во Франции XVIII, так и в России XX века, а также об исключительно кровавом режиме красных кхмеров, истреблявшем людей именно по социальному признаку, и кроме того, обратить внимание на то, что маркируемые как «этнические или расовые» современные конфликты имеют очевидную социальную подоплеку и вызваны стремлением депривированных групп получить доступ к ресурсам, от которых они отрезаны. Сомнительными выглядят и заявления, будто бы «в фундаменте большинства современных государств находится ... этническая доминанта» [28] и что «мигрантофобии имеют выраженную этническую этиологию» [184].

Научная добросовестность, впрочем, заставляет авторов в другом месте книги признать, что «конфликты культурных стандартов могут происходить (и происходят) и между группами одной этнической принадлежности, например, между русскими жителями мегаполиса и приезжими русскими из малого города или села. Но эти конфликты не имеют, как правило, резонанса в информационной среде, а потому остаются вне внимания общественности, в отличие от эскалации такого же в своей основе и модели развития конфликта, где противостоящими сторонами являются разные этнические группы» [94]. Позволю себе небольшое лирическое отступление. В 1992-93 гг. мы с коллегами исследовали ситуацию с первой волной постсоветских вынужденных мигрантов в Белгородской области. Мигранты эти были русскими, но набор стереотипов местного населения в их отношении ничем не отличался от приводимых в рецензируемом труде и относящихся к недавним беженцам с Украины. Совпадение буквально дословное: «чрезмерные претензии», «иждивенчество», «им все должны», «для беженцев делается 
больше, чем для местных, и за счет местных» [177-178]. Корень мигрантофобии, выходит, все же не в «этничности», а в ксенофобии, частным случаем которой и является мигрантофобия.

Социальные взаимодействия рассматриваются в книге как «отношения между этносами» [5], обладающими собственными групповыми «интересами» [38], которые порождают «неутихающие противоречия» [28]; не подвергается сомнению существование «этнических преступных группировок» [8]. Авторы воспроизводят представления американских ученых, противопоставляющих класс как открытую социальную группу группам этническим, состав которых якобы определен, а границы четко выражены [27]. Такое утверждение в какой-то мере справедливо для американского общества с его культом self-made man, с одной стороны, и расовым принципом one-drop rule - с другой. Но оно неприменимо, например, к Бразилии, где в результате длительной и интенсивной метисации, возведенной в государственный принцип, существует бесконечная градация оттенков кожи, размывающая «четко выраженные границы», и где приписываемая обществом расовая принадлежность человека напрямую зависит от его социального статуса. Можно вспомнить еще меткую поговорку жителей Антильских островов, согласно которой «богатый негр является мулатом, а бедный мулат - негром». Утверждение о невозможности поменять свою этническую принадлежность опровергается даже американскими учеными, давно обратившими внимание на неустойчивость самоидентификации людей от переписи к переписи. Кстати, авторы рецензируемого труда говорят то об этнической принадлежности, то об идентичности, то о межэтнической напряженности, то о «раздражении», которое испытывают по отношению друг к другу «люди разной этнической принадлежности» - что, как мы понимаем, отнюдь не одно и то же.

К достоинствам книги следует отнести нечасто встречающееся критическое обсуждение методологии исследования, в частности границ применимости метода фокусгрупп, разработанного на либерально-демократическом Западе и не всегда дающего адекватные результаты при работе в группах с выраженными коллективистскими и традиционалистскими установками. Необходимость адаптировать любой инструментарий к конкретным условиям - проблема известная, в том числе по международным тестам IQ, сравнительным исследованиям грамотности в разных странах, личностному тесту МMPI, результаты которых сильнейшим образом обусловлены культурным контекстом (географическим и временным), в котором создавались методики. В данном случае камнем преткновения стало не содержание вопросов или их формулировка, но сама процедура, предполагающая необходимость публично выражать свою точку зрения в присутствии старших или более авторитетных членов сообщества, поэтому решение отказаться в ряде случаев от проведения фокус-групп и заменить их углубленными интервью выглядит логичным и обоснованным.

В то же время не подвергается сомнению пригодность анкетирования для изучения «этничности». Впрочем, что именно пытаются изучать авторы с его помощью, не вполне понятно. Несмотря на упоминание «исследовательских целей, заявленных в проекте» [56], цели эти, в сущности, нигде определенно не заявлены: речь идет попеременно о «межнациональной ситуации», «межнациональных отношениях», «межнациональных 
установках» (иногда сводимых к их аффективному компоненту, именуемому «балансом национальных установок»), «этническом самосознании», «этнической/национальной идентичности», причем содержание всех этих терминов нигде не раскрывается. Очевидно, однако, что авторы, в отличие, скажем, от Р. Брубейкера, не мыслят себе «этничность вне групп» (ср. «Под межэтнической напряженностью понимается нарушение взаимоотношений в обществе, возникающее из-за обостряющихся противоречий между этническими группами» [112]), о чем свидетельствует, в частности, выделение в качестве основных факторов конфликтности «ингруппового фаворитизма» и «аутгруппового негативизма», а также отождествление несогласия с утверждением «в наше время человеку необходимо считать себя частью своей национальной группьл» с отсутствием национальной идентичности [137].

Наряду с группоцентризмом, необходимо отметить заложенный в исследовательский инструментарий государствоцентризм. Так, вопросы об отношении к мигрантам формулируются с позиции государства, а не индивида или даже общества: «нашей стране нужны/не нужны мигранты» [95], «нужны» такие, а не другие [194]. Логичным продолжением такого прагматично-потребительского подхода становится интерпретация позиции респондентов: «как не нужны, а кто будет дороги убирать, полы мыть» [194] - как проявления «здравого смысла» и толерантности, а не нетерпимости и отторжения, сами же мигранты рассматриваются лишь как объекты государственной политики.

Отсутствие четкого понимания, что же, собственно, хотят исследовать/измерить авторы рецензируемой монографии, а также гипертрофированное внимание к «этническому фактору» проявляются и в более чем странной трактовке первой и второй чеченских кампаний и даже гипотетической «войны с соседней страной» как «межэтнических конфликтов, санкционированных государством» [200], и в попытке поисков в истоке «межэтнических конфликтов» «революционного сознания», а в любых «действиях, приводящих к конфликтам и даже насилию» - например, в городских бунтах этнической составляющей [244-250].

На инструментальном уровне тщетность попыток объективировать субъективное видна в расплывчатых формулировках вопросов, предъявляемых респондентам. Приведу только два примера. При выяснении отношения к религии «респонденту не разъяснялось, что имеется в виду под формулировкой “верующий”, “атеист” и др. Ему самому нужно было определить для себя значение этих категорий и отнести себя к одной из них» [129]. Не вполне понятно также, что можно узнать с помощью вопроса «насколько в Вашем городе/селе важна национальность человека для устройства/назначения [на ту или иную должность/работу]?». По приведенным выдержкам из интервью видно, насколько поразному понимают его смысл респонденты: одни рассуждают о том, нужно ли учитывать «национальность», другие - о том, учитывается ли она. Авторы книги и сами понимают, что большинству людей «сложно представить, чем руководствуются при назначении на высокие должности. Это вопрос, выпадающий из привычной практики человека. Поэтому, отвечая на него, респонденты зачастую начинали “воображать”, представлять себе, как это может происходить» [272]. На фоне множества приводимых в книге мнений людей разных национальностей о том, что не принадлежность к определенной категории, а «полезные 
связи» («с кем во дворе дружил», «с кем в институте учился», «своя команда, с кем раньше работал»), а также «богатые родители» или «родственники на руководящих постах» являются ресурсом для карьеры [270, 273 и др.] особенно абсурдно выглядит дважды повторенная мысль о том, что на территории России нет «русских общин», а потому русские не могут рассчитывать на помощь своей «диаспоры» [282, 294-295].

К числу безусловных достоинств рецензируемого труда относится подробный и аргументированный анализ «фундаментального вклада... государственнобюрократического аппарата в формирование и поддержание враждебности по отношению к иноэтничным группам населения», опровергающий распространенное представление о повышенном уровне ксенофобии в российском обществе [204]. Вклад этот включает официальные указания правоохранительным органам об особом контроле над выходцами с Северного Кавказа, появившиеся с середины 1990-х годов, закрепление практик этнически избирательного регистрационного учета на протяжении 2000-х годов, вовлечение в осуществление контроля над выходцами из северокавказских республик, Закавказья и Средней Азии различных ведомств (миграционной службы, органов ЗАГС, Госкомимущества, надзорных органов), а также муниципалитетов, руководства школ и населения в целом.

Следующим шагом могло бы стать осознание того вклада, который вносят в создание «межэтнической напряженности» массовые опросы, в ходе которых вам предлагают задуматься над тем, есть ли в мире «национальности, которые вы не уважаете»; нравится ли вам, когда в вашем присутствии «говорят на непонятном языке», правда ли, что «некоторые национальности отличаются агрессией и склонностью к криминалу» [82], а также как вы поступите, если в уличной драке «молодые люди иной национальности ... убьют парня вашей национальности» [97]. Однако этого осознания пока не происходит.

\section{ЛИТЕРАТУРА}

Епихина Ю.Б., Черныш М.Ф. (Ред.) (2017). Социальные факторы межэтнической напряженности в России. Москва: ФНИСЦ РАН. 336 с. 


\section{ELUSIVE ETHNICITY}

\section{Review of the book «Social factors of interethnic tension in Russia»}

\section{ELENA FILIPPOVA}

In line with the tradition established in the Russian school of ethnosociology, which considers social interactions, contradictions and conflicts through the prism of "inter-ethnic relations", the central concept of the book here reviewed is "inter-ethnic tension". To what extent is such a universalization of "ethnicity" justified as an explanatory mechanism of social processes? What does it explain and what can it not explain? What is the result of absolutizing ethnicity as a property inherent in each individual and predetermining his belonging to a group? These and other issues are discussed in the review.

Key words: ethnicity, interethnic tensions, ethnocentrism, groupism, state-centrism.

ElENA FiLIPPOVA (elena_filippova89@yahoo.fr), INSTITUTE of ETHNOLOGY AND ANTHROPOLOGY RUSSIAN ACADEMY OF SCIENCES, RUSSIA.

DATE RECEIVED : MARCH 2019.

\section{REFERENCES}

Epikhina YU.B., Chernysh M.F. (Eds.) (2017). Sotsial'nyye faktory mezh·etnicheskor napryazhennosti v Rossii [Social factors of interethnic tension in Russia]. Moscow: FNISTS RAN. 336 p. (In Russ.) 